\title{
THE ELECTROCARDIOGRAM IN PRIMARY ENDOCARDIAL FIBROELASTOSIS
}

\author{
BY \\ PETER VLAD, RICHARD D. ROWE, AND JOHN D. KEITH
}

From the Hospital for Sick Children and the Department of Pediatrics, University of Toronto, Toronto, Ontario, Canada

Received September 4, 1954

Primary endocardial fibroelastosis (EFE) in infancy has become a widely recognized pathological entity but it is only latterly that clinical diagnosis has been attempted. Although there are now numerous reports of the clinical picture of the disease, electrocardiographic studies are scanty.

Before 1953 there were 30 electrocardiograms of previously reported cases (Weinberg and Himelfarb, 1943; Vulliamy, 1947; Craig, 1949; Glynn and Reinhold, 1950; Stadler et al., 1950; Lewis, 1951 ; Emery and Illingworth, 1951 ; Collier and Roshan, 1951 ; Hill and Reilly, 1951 ; Edmonds and Seelye, 1951; Blumberg and Lyon, 1952; Johnson, 1952; Bonham-Carter et al., 1952; Prec and Cassels, 1952). Rhyhtm disturbances were noted in fourteen: auricular tachycardia in two; nodal rhythm with short P-R interval in one; and paroxysmal multifocal ventricular extrasystoles in one instance. Alterations in conduction occurred in about one-third of the cases: prolonged P-R interval in six and atrio-ventricular dissociation in five cases; the latter finding was observed at, or shortly after, birth in four tracings. Bundle branch block was rare-left once and right three times. A slight or moderate degree of right axis deviation was present in 14 instances, left axis deviation occurring only once. Flattening or inversion of the T wave in two or all of the standard leads was reported in 10 patients.

Since 1952 several complete electrocardiograms have been published (Adams and Katz, 1952, 1953; Clément et al., 1952; Schweisguth and Nouaille, 1952; Lambert et al., 1953; Leteer, 1953; Metianu et al., 1954). It has become increasingly clear in this period that the electrocardiogram will assist clinical diagnosis. Most authors note left ventricular hypertrophy to be present.

The purpose of this paper is to analyse the electrocardiographic findings in a relatively large group of cases with post-mortem confirmation.

\section{MATERIAL}

Twenty-three electrocardiograms with standard, unipolar limb and præcordial leads have been assembled. Ten of these have been published (Adams and Katz, 1952, 1953; Clément et al., 1952; Schweisguth and Nouaille, 1952; Leteer, 1953; Lambert et al., 1953; Metianu et al., 1954). Of the remaining cases, seven were patients in the Children's Memorial Hospital, Montreal and the Children's Hospital, Buffalo, New York, while six were observed in the Hospital for Sick Children, Toronto. The age at death in this group ranged from two months to seven years. All had an anatomical diagnosis of primary endocardial fibroelastosis with or without valvular involvement. None of these patients was found to have evidence of coronary calcification or myocardial infarction at necropy. Only one had an associated congenital anomaly of the heart (Case 21 with preductal 
coarctation of the aorta). In five instances (Cases $4,5,15,16$, and 17) there was mention in the necropsy protocols of cellular infiltration of the myocardium in addition to the characteristic mural endocardial thickening and marked left ventricular hypertrophy. In 20 instances where complete clinical and pathological data were available, heart failure with pulmonary congestion, hepatomegaly, and dilated right atrium and ventricle was a prominent feature terminally.

\section{Electrocardiographic Criteria of Ventricular Hypertrophy}

Left Ventricular Hypertrophy. The presence of two or more of the following signs has been taken as direct evidence of left ventricular hypertrophy.

1. Voltage of $\mathrm{R}$ in V5 or V6 greater than the maximum normal for age.*

2. Voltage of $S$ in $V 1$ or $V 2$ greater than the maximum normal for age.

3. Secondary $\mathrm{T}$ wave inversion in V5 and/or V6.

4. Ventricular activation time in V6 greater than maximum normal for age.

5. R/S ratio in V1 (Gros et al., 1951): less than 1.0 under the age of 1 year; less than 0.3 between 1 and 5 years; and less than $0 \cdot 1$ after 5 years.

In addition, in the presence of direct signs of right ventricular hypertrophy, indirect evidence of left ventricular hypertrophy is believed to be provided by the persistence of a $Q$ wave in V5 and/or V6 in the presence of clockwise rotation and the absence of right bundle branch block.

Right Ventricular Hypertrophy. Taken as direct signs of right ventricular hypertrophy were at least one of the following.

1. Voltage of $\mathrm{R}$ in V1 or V2 greater than the maximum normal for age.

2. Voltage of $\mathrm{S}$ in V5 or V6 greater than the maximum normal for age.

3. Ventricular activation time in V1 greater than the maximum normal for age.

\section{ELECTROCARDIOGRAPHIC FindingS}

Rhythm. Apart from Case 8 which showed persistent multifocal extrasytoles, sinus rhythm was the rule.

Conduction. The shortest $\mathrm{P}-\mathrm{R}$ interval was in a case with Wolff-Parkinson-White (W-P-W) syndrome (Case 22). The P-R interval was prolonged in less than one-third of the cases and may be so before the administration of digitalis (Case 6). Complete heart block was not encountered in this series. Partial right bundle branch block or complete left bundle branch block appears to be uncommon (once each).

$P$ Wave. In 14 cases the $P$ wave showed abnormalities: right auricular hypertrophy alone was present in two; left auricular hypertrophy alone in nine, and combined auricular hypertrophy in three cases.

QRS Complex. Apart from the cases of W-P-W syndrome and left bundle branch block the duration of QRS was normal. Sixteen cases had vertical or semi-vertical electrical position, ÂQRS usually between $+80^{\circ}$ and $+100^{\circ}$, prominent $\mathrm{S} 1$, and clockwise rotation. Three cases occupied an intermediate position, having the ÂQRS at $+30^{\circ}$, while two showed also anticlockwise rotation with $Q$ in lead I. Semi-horizontal position occurred four times under special circumstances, viz: left bundle branch block (Case 23), complicating congenital anomaly (Case 21) and marked right ventricular hypertrophy (Cases 1 and 17). Left axis deviation ( $\hat{\mathrm{A} Q R S}$ less than $+30^{\circ}$ ) was present only twice, in each instance the position being horizontal. Unipolar limb leads aVR had a predominantly negative deflection apart from Cases 1, 5, and 22. The voltage in aVL and aVF was normal with the exception of Case 21. The QRS pattern over the right præcordium was commonly $\mathrm{rS}$ and over the left præcordium $\mathrm{qR}$. The transitional complex tended to be shifted to the left. With the exception of Case 22, the ventricular activation time was always longer in V6 than in V1 with the exception of Case 1. It exceeded the normal value for age in V6 in nine and in V1 in three cases.

* Maximum normal values for age are based on those of Ziegler (1951). 
$T$ Wave. Inversion of $\mathrm{T}$ waves in the left-sided chest leads was extremely common; only three cases not showing this abnormality. The $\mathrm{T}$ wave may be inverted in any standard lead but it was abnormal in $\mathrm{I}$ and/or II in two-thirds of our cases.

$S-T$ Segment. This was normal or only slightly depressed in all cases except that with the W-P-W syndrome.

\section{Discussion}

Three of 23 cases in this series have electrocardiograms that are completely different from the remainder (Table I). One (Case 21) has no evidence of ventricular hypertrophy and left auricular

\section{TABLE I}

\section{Pattern}

No ventricular hypertrophy-left auricular hypertrophy only

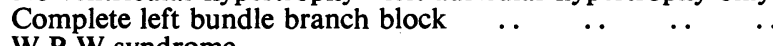
W-P-W syndrome

Left ventricular hypertrophy

Right ventricular hypertrophy ..

Total ..

$\begin{array}{cccc} & & & \begin{array}{c}\text { No. of } \\ \text { Cases }\end{array} \\ \ldots & \ldots & \ldots & 1 \\ \ldots & \ldots & \ldots & 1 \\ \ldots & \ldots & \ldots & 1 \\ \ldots & \ldots & \ldots & 16 \\ . & . & \ldots & 4 \\ \ldots & \ldots & \ldots & 23\end{array}$

Auricular hypertrophy: left 9, right 2, combined 3

hypertrophy was its sole anomaly; a second (Case 22), exhibited W-P-W syndrome, and a third (Case 23) showed complete left bundle branch block. While the first and last tracings associated with cardiomegaly may only suggest left ventricular disease, this may still be an important diagnostic clue on occasion.

Left Ventricular Hypertrophy. Electrical changes due to left ventricular enlargement or thickening are recorded in 16 of the 23 cases. The criterion invariably satisfied in these was T wave inversion in V6. Abnormally tall R in V6 (75\%) or low R/S ratio in V1 (64\%) were common. Delayed ventricular activation time in left chest leads $(53 \%)$ or increased voltage of S in V1 $(40 \%)$ were less frequently encountered.

Reduced electrical potentials may occasionally be encountered (Fig. 1). Such factors as myocardial anoxæmia, pleuro-pericardial effusion or œdema due to cardiac failure in its terminal stages may be responsible for this phenomenon as in Case 2 and Case 9. With the exception of the few cases with anatomical complications (coarctation of the aorta, Case 20) or conduction disturbances (Cases 21 and 22) the electrocardiogram followed more or less the same pattern: vertical or semivertical position, tall $\mathbf{R}$ or $\mathrm{qR}$ waves in V5 and V6 with secondary inversion of the T wave (Fig. 2).

Right Ventricular Hypertrophy. Because there is difference of opinion as to whether a heart in vertical electrical position with clockwise rotation and left ventricular hypertrophy indicates combined ventricular hypertrophy, we have avoided attaching significance to its presence. None the less, over half of the remaining 13 cases showed this combination.

In four instances (Cases 1, 5, 15, and 17) the initial electrocardiograms showed predominant signs of right ventricular hypertrophy. These are the only examples of frank right axis deviation (ÂQRS over $+100^{\circ}$ ). Predominance of the positive deflection over the right præcordium is frequent (three of four cases). Even qR patterns due to extreme right heart overload may be recorded as in Case 1 (Fig. 3). Two of these cases also showed a horizontal electrical position, a sign only rarely encountered in the majority group and then confined to the complicated cases (coarctation of the aorta; left bundle branch block).

Only one of this particular group (Case 17) failed to show some left ventricular hypertrophy on subsequent tracings. In fact even in the initial electrocardiograms there were findings suggestive of this eventuality in three instances: diphasic or negative $T$ waves in V5 or V6 twice, $Q$ waves and long ventricular activation times over the left of the præcordium in the presence of marked clockwise rotation.

Two cases observed in this centre at the height of the initial congestive heart failure and subsequently over a period of many months showed startling reversal of electrocardiographic pattern. In one (Fig. 6) right ventricular hypertrophy was replaced (with the relief of symptoms) by pure left ventricular hypertrophy 


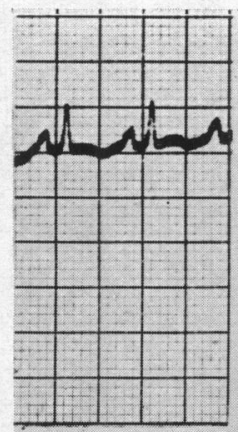

I

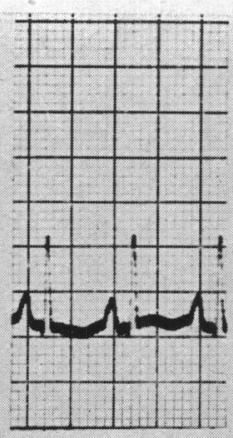

II

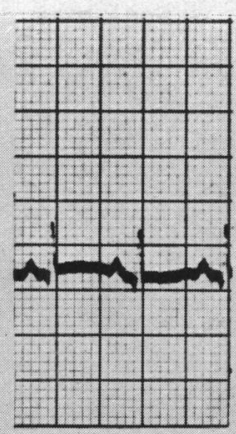

III

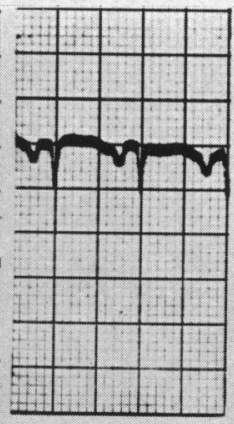

VR

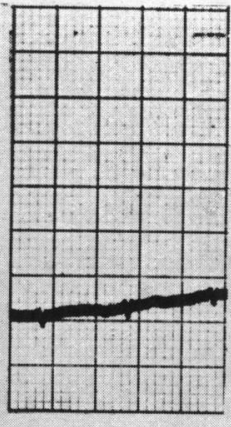

VL

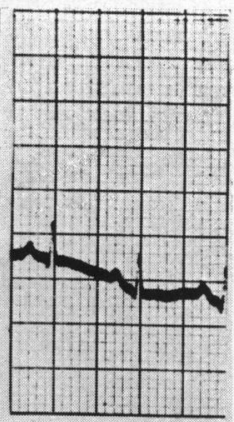

VF
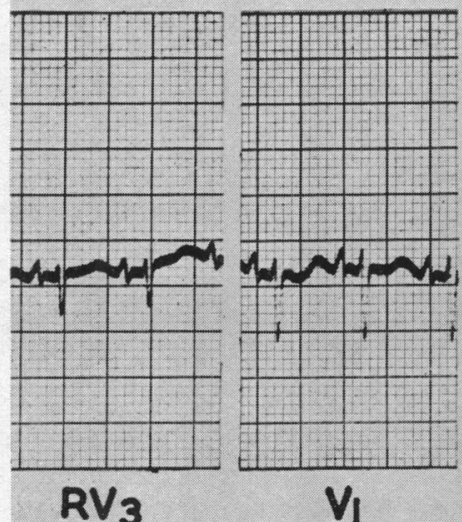
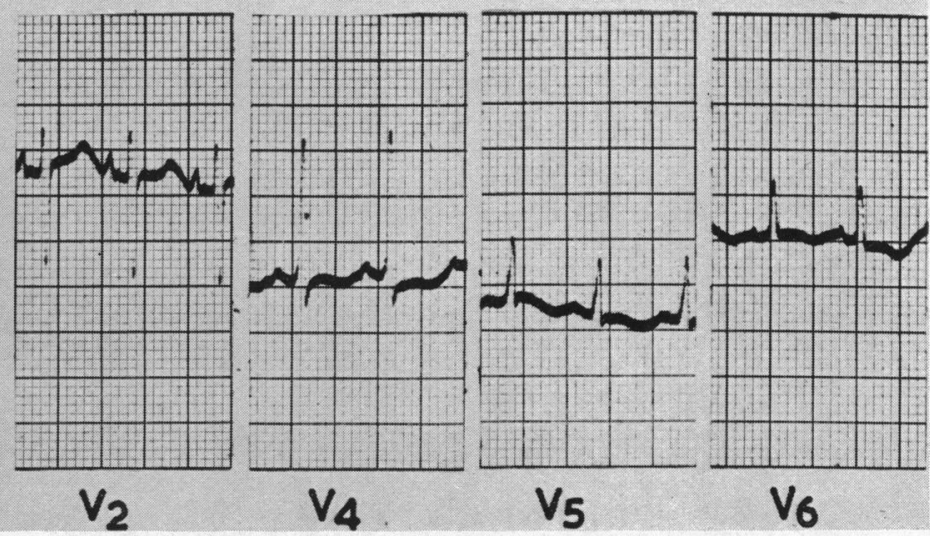

FIG. 1.-Boy, aged 2 months (Case 2), 8/12/52. Despite the lack of increase in voltage of QRS this tracing shows left ventricular hypertrophy on the basis of predominant negative deflections over the right and predominant $\mathrm{R}$ with negative $\mathrm{T}$ waves over the left præcordium. The autopsy showed marked left ventricular hypertrophy and pleuro-pericardial effusion.

electrically. This phenomenon was repeated in three later bouts of heart failure. Case 1, also improved by digitalis, was seen to have left ventricular hypertrophy in the electrocardiogram after four months of treatment. Three further cases (Cases 6, 9, and 21), while presenting predominant left ventricular hypertrophy, and included for that reason in the majority group, had associated direct signs of right ventricular hypertrophy such as abnormally high voltage of $\mathrm{R}$ in V1 or V2 (Fig. 4).

The practical application of this information is, of course, that EFE need not necessarily be excluded from the differential diagnosis merely because of the lack of left ventricular strain in the cardiogram. On the other hand it is striking that all the patients with marked right ventricular hypertrophy either had a chronic course, as in Case 1, or were atypical anatomically, as in Case 17 (of Metianu) with four chamber involvement and mild endocardial changes. Fulminating cases by comparison have not shown any right ventricular hypertrophy in this series.

Edwards (1953) has suggested recently an anatomical division of primary endocardial fibroelastosis into a 'contracted' type with a small left ventricle and a dilated and greatly hypertrophied right heart, and a 'dilated' type with a dilated and noticeably hypertrophied left ventricle. From an electrocardiographic viewpoint it is possible that the group with predominant or associated direct signs of right ventricular hypertrophy are the cases of the "contracted" type, whereas the others may well correspond to the 'dilated' type.

Auricular Enlargement or Hypertrophy. Signs of auricular enlargement in the electrocardiogram were almost always noted in cases showing direct signs of right ventricular hypertrophy (Fig. 4). It was rather 
less frequently seen in the cases with left ventricular hypertrophy. Chronicity of symptoms seemed to be the important factor governing this change.

It is not suggested that the electrical pattern so commonly encountered in primary endocardial fibrcelastosis is specific for this condition. Identical changes may be recorded in patients suffering from coarctation of the aorta, patent ductus arteriosus, complete transposition of the great vessels, truncus arteriosus, tricuspid atresia with transposition of the great vessels, and aortic stenosis. There are means other than electrical by which endocardial fibroelastosis may be differentiated from such anomalies. However, extreme left ventricular hypertrophy in an infant with preductal coarctation of the aorta in congestive heart failure would suggest its association with EFE. Infants with physical signs of ventricular septal defect but marked left heart strain in the cardiogram may be similarly suspect.

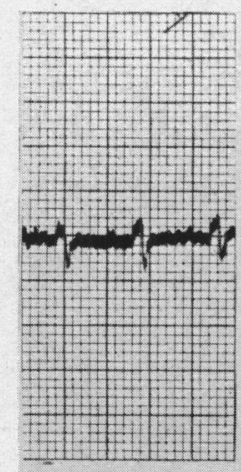

I

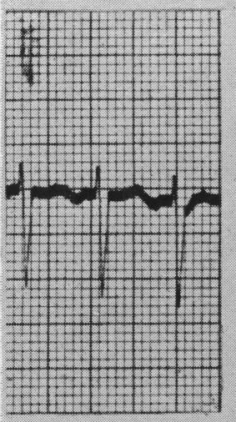

$\mathrm{RV}_{3}$

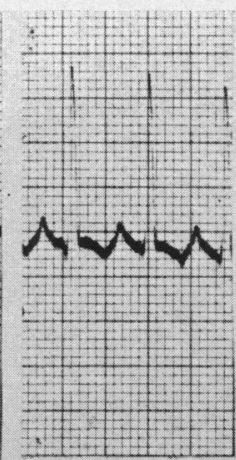

II

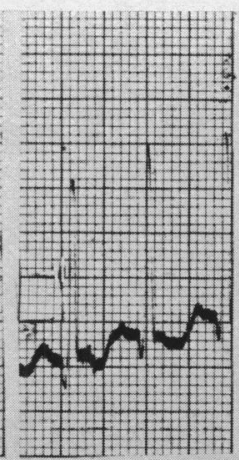

III

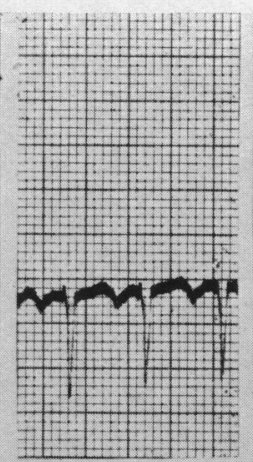

AVR
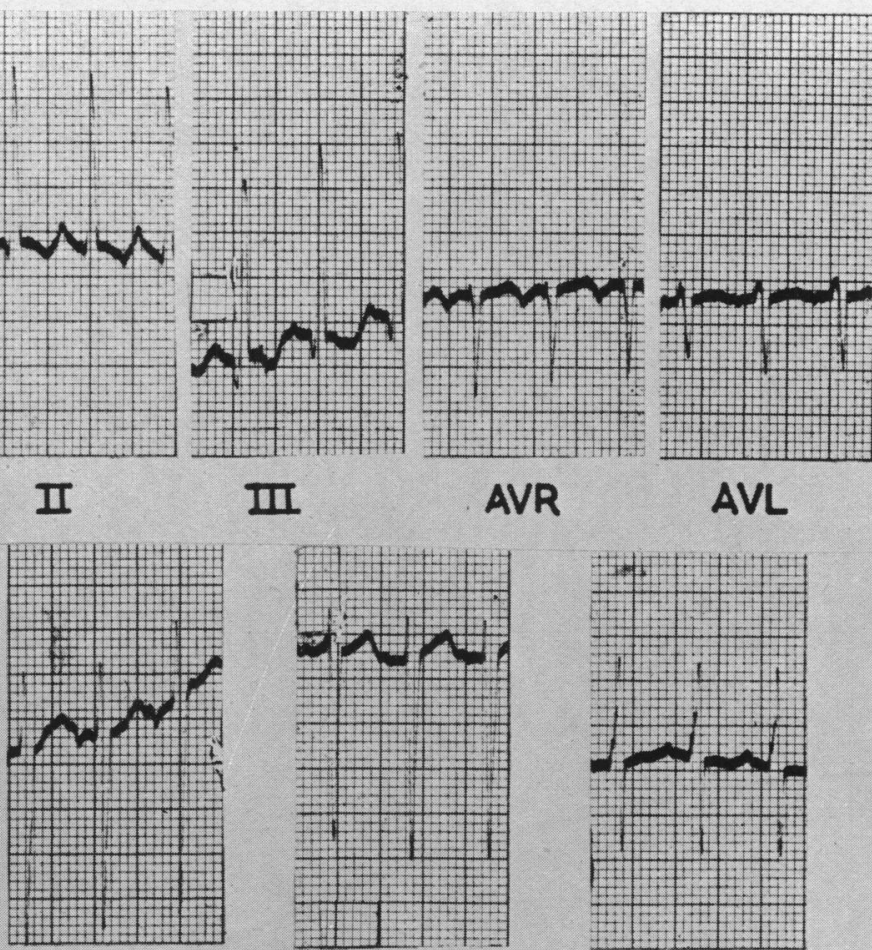

$V_{1}$

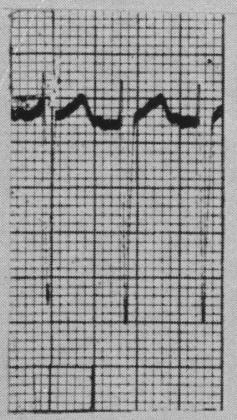

$V_{3}$
AVL

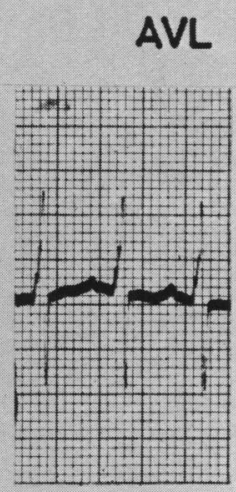

$v_{5}$

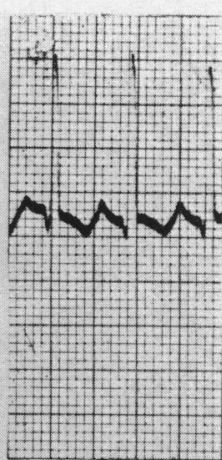

AVF

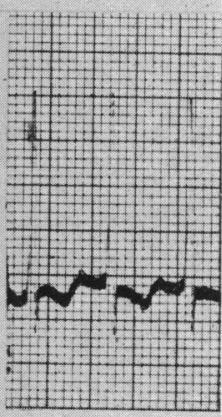

$V_{6}$

FIG. 2.-Girl, aged 17 months (Case 18), 11/3/53. The common pattern in this series: vertical electrical position; marked clockwise rotation; high voltage of QRS; inverted T wave over the left præcordium (left ventricular hypertrophy).

The conditions in which the electrocardiogram renders crucial aid in ætiological diagnosis are found in the group of large hearts with failure in infancy unaccompanied by central cyanosis, murmurs, or shunts. This clinical picture is presented by endocardial fibroelastosis, interstitial myocarditis, glycogen disease of the heart, and left coronary artery arising from the pulmonary artery (LCPA).

According to Miller (1954) the electrocardiogram in glycogen disease of the heart shows a left heart strain pattern characterized by severely depressed S-T segments with sharply inverted $T$ waves in the limb leads. The same author believes that in interstitial myocarditis general flattening or loss of amplitude of T waves in every lead in which the QRS complex is upright and minimal S-T segment changes with variations from record to record form a dependable electrical pattern. Others feel that the development of conduction disturbances is a helpful sign.

There has been more noticeable difficulty in distinguishing endocardial fibroelastosis from the much less frequent syndrome of left coronary artery arising from the pulmonary artery. While no case of endocardial 
fibroelastosis has shown signs of myocardial ischæmia, injury or necrosis, ${ }^{*}$ seven of the eight complete tracings. in LCPA (McKinley et al., 1951; Dagonet, 1952; Holzmann, 1952; Taussig, 1953; Keith, 1954; Miller, 1954; Schlichter et al., 1954) have signs of myocardial infarction of the anterolateral, anteroseptal or high anterolateral types (Fig. 5). A Q wave in lead I was rare in EFE (3 of 23 cases), was always part of a qRs pattern, and was positional. In LCPA it was frequent (15 of 19 cases: Bland, et al., 1933; Eidlow and Mackenzie, 1946; Lyon, et al., 1946; Kaunitz, 1947; Gasul and Loeffler, 1949; Gouley, 1950; McKinley, et al., 1951; Dagonet, 1952; Hartenstein and Freeman, 1952; Holzmann, 1952; Keitzer and Rochat, 1952; Taussig, 1953; Keith, 1954; Miller, 1954; Schlichter, et al., 1954), and was part of a qR or QR complex, being. usually the result of necrotic changes. The presence of such ischæmic and necrotic findings should exclude EFE but does not, of course, rule out other causes of myocardial infarction in infancy, such as coronary

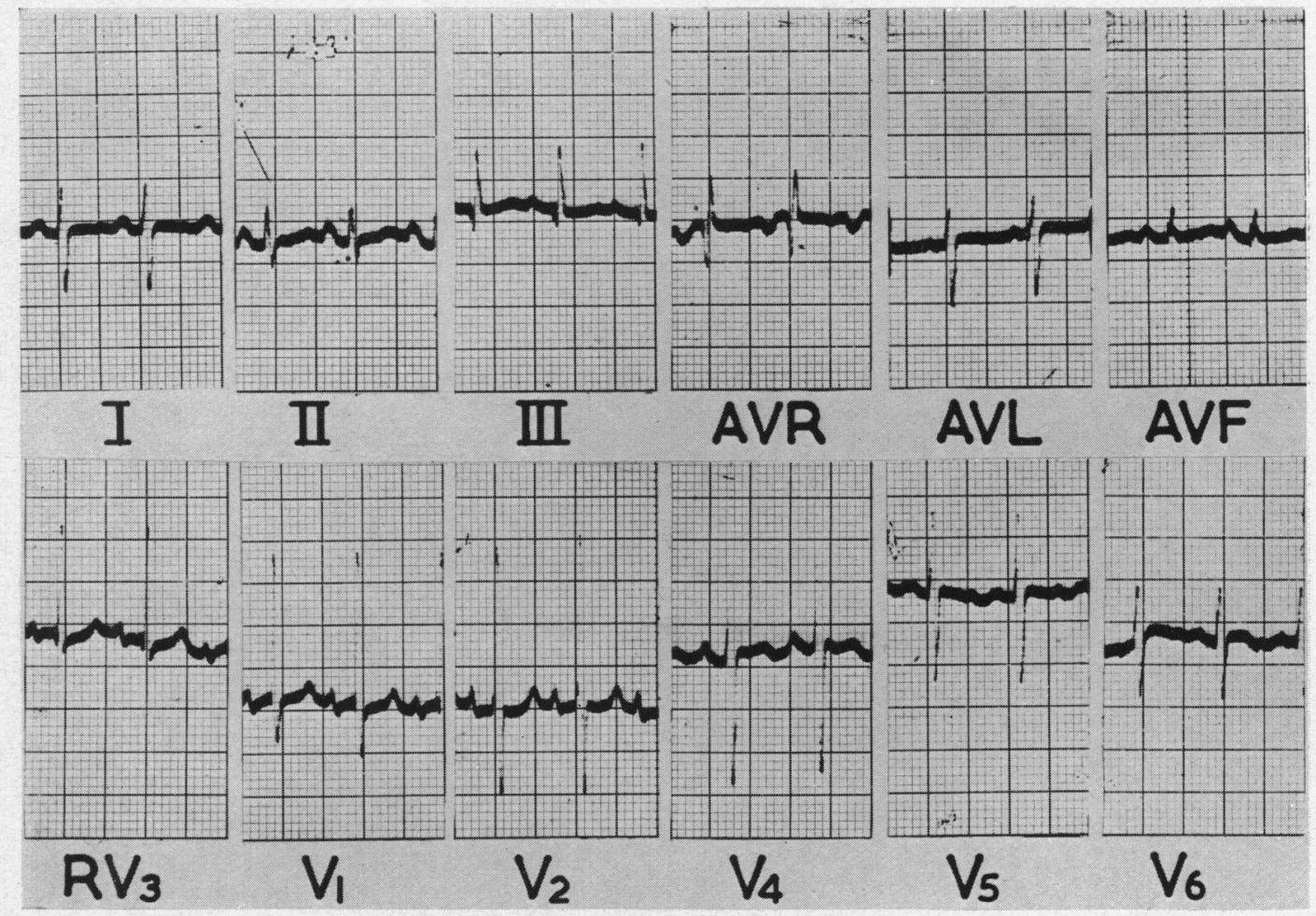

FIG. 3.-Boy, aged 3 weeks (Case 1), 5/1/53. Electrocardiogram showing frank right ventricular hypertrophy including a $\mathrm{qR}$ pattern in the right præcordial leads.

calcification, myocardial tumours, periarteritis nodosa, or coronary atherosclerosis. Ischæmic changes may be obtained also from the dying heart. Complete left bundle branch block with widening of the QRS has been encountered in both conditions, but possibly its appearance at an early age may favour LCPA. Low voltage $T$ wave inversion in the standard leads may be seen in both conditions. The flattening may be due to generalized myocardial hypoxæmia, diffuse generalized fibrosis of the myocardium, or extracardiac collections of fluid. Where T wave change is due to hypertrophy as in EFE, the shape is asymmetrical; where it is the result of infarction, the $T$ wave is symmetrical with late inversion and is seen in other leads of the electrocardiogram.

Coronary calcification, another condition that may have the same clinical picture as LCPA or EFE, is interesting because it may show the electrocardiographic features of both: vertical or semivertical heart with clockwise rotation and left ventricular hypertrophy, and, in addition, signs of ischæmia or necrosis of the apex and the antero-lateral wall of the left ventricle.

* Case 22 (Leteer, 1953) was reported as showing subendocardial ischæmia, but because of the presence of W-P-W syndrome it is difficult to ascribe significance to $\mathrm{S}-\mathrm{T}$ segment changes. 


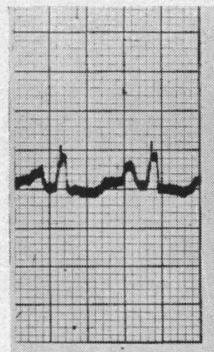

I

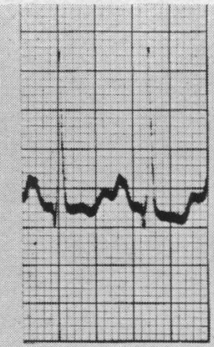

II

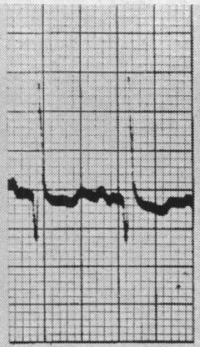

III

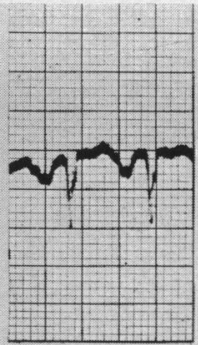

AVR

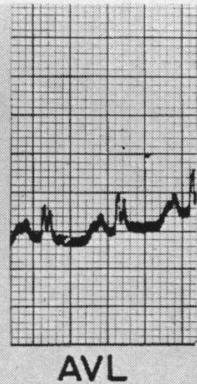

AVL

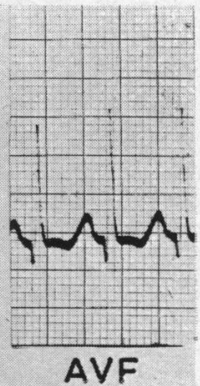

AVF

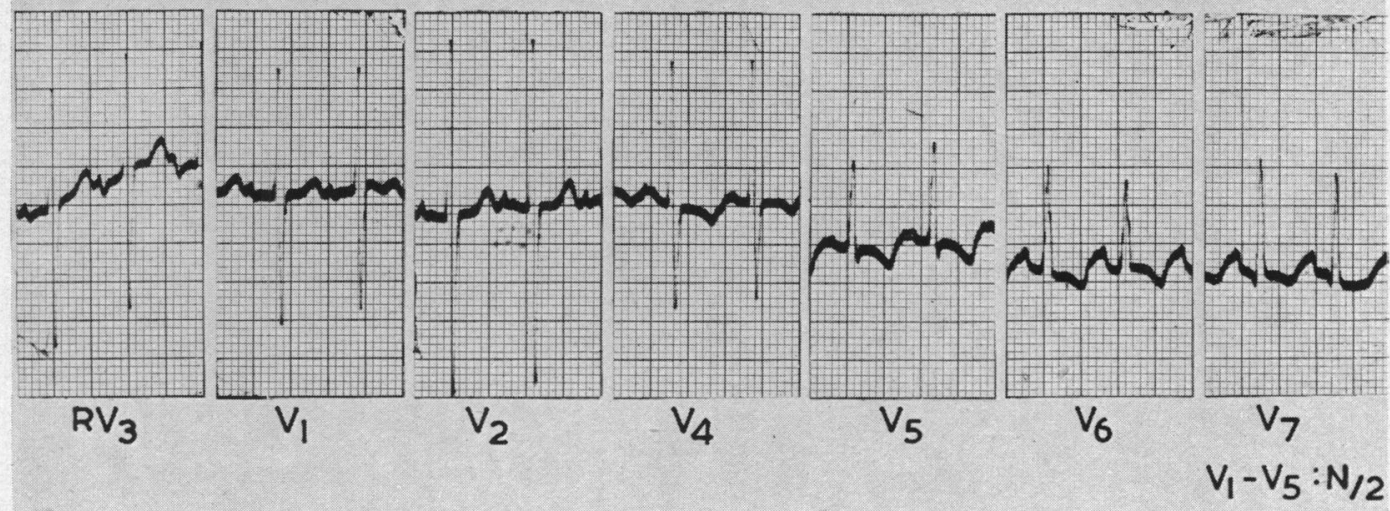

FIG. 4.-Girl, aged $3 \frac{1}{2}$ months (Case 6), 18/12/52. This tracing shows in addition to the obvious signs of left ventricular hypertrophy (high voltage $R$ wave and $T$ inversion in the left chest leads) tall $R$ waves over the right præcordial leads indicating right ventricular hypertrophy or dilatation.

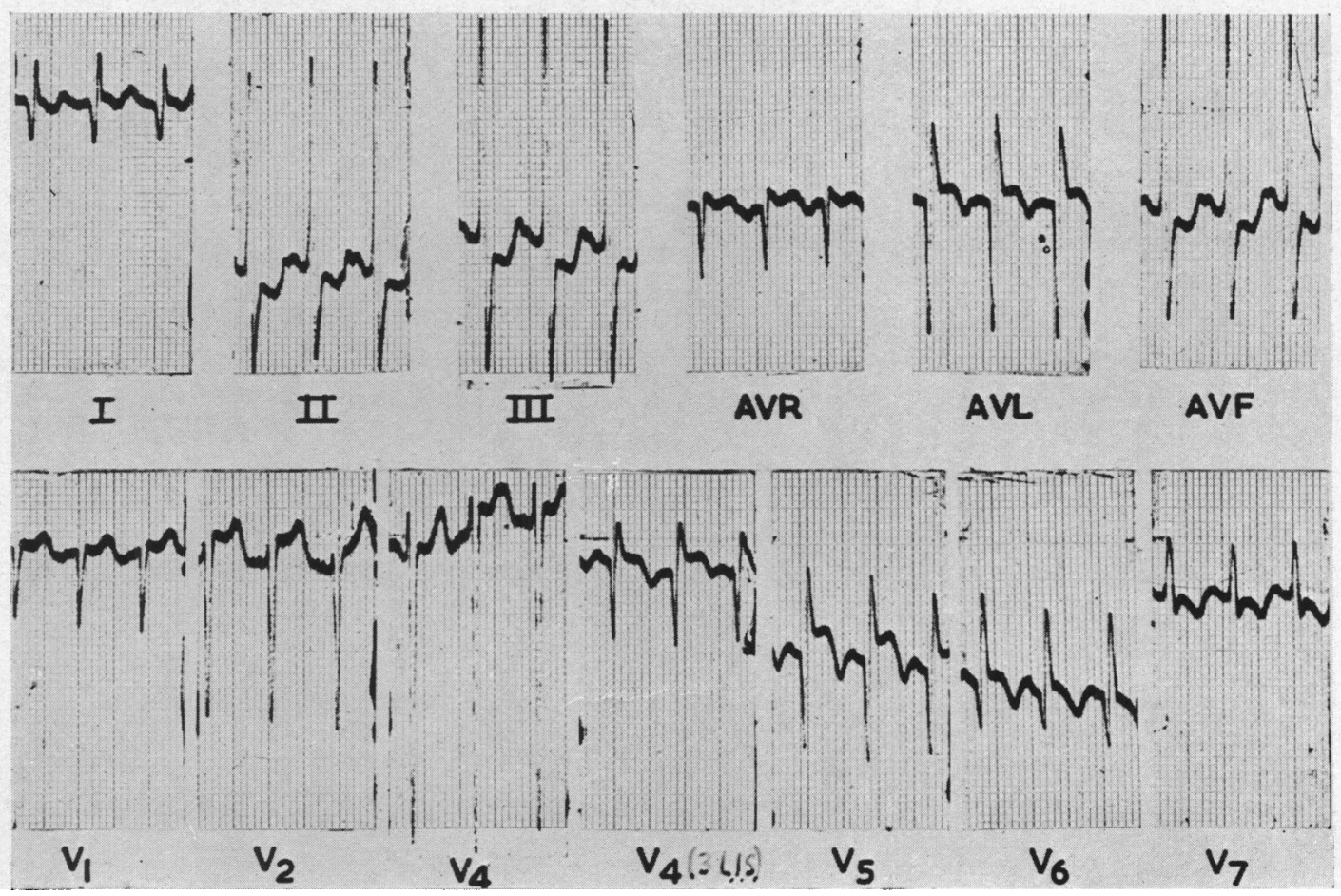

Fig. 5.-Boy, aged 4 months. Electrocardiogram of a case of left coronary artery arising from the pulmonary artery showing antero-lateral infarct. 


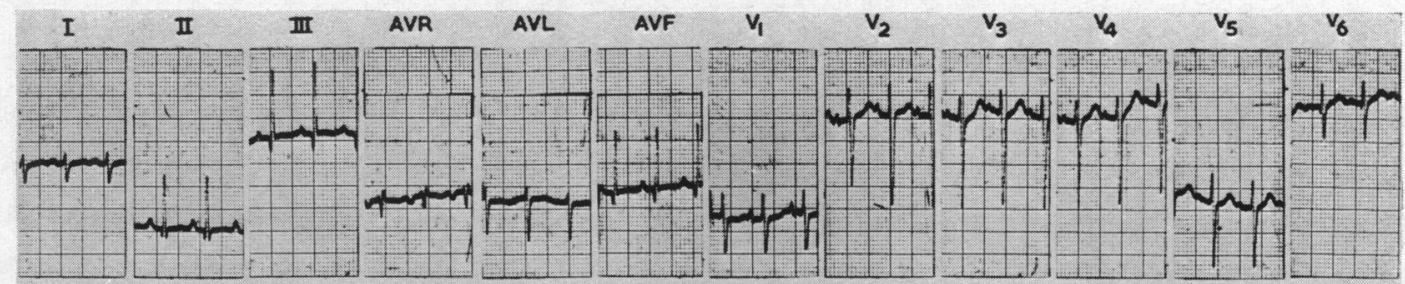

A. 15.5 .51

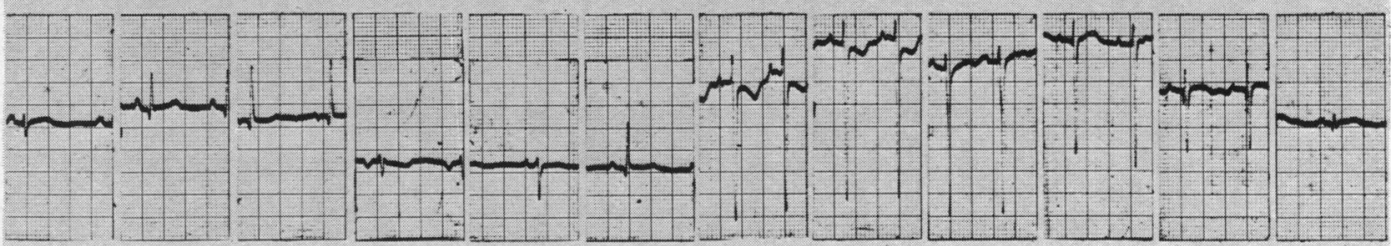

B.21.5.5।

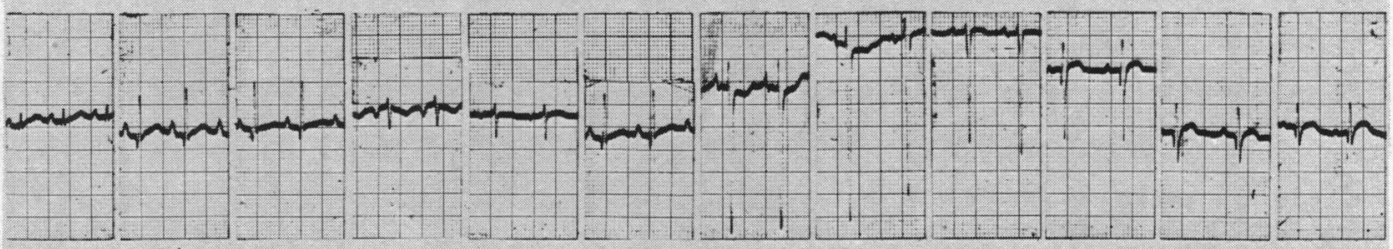

C.23.5.51

FIG. 6.-Girl, aged 13 months. Electrocardiograms illustrating the findings in Case 15 . (A) In congestive heart failure before digitalization: vertical electrical position with an ÂQRS of $+120^{\circ}$, transitional complex and $q$ wave in V6. Note that the only suggestion of left ventricular hypertrophy lies in the persistence of $\mathrm{q}$ wave in $\mathrm{V} 6$ and the ventricular activation time in V6 being longer than in V1. (B) After two days on digoxin: ÂQRS now $+90^{\circ}$, transitional complex in V5, q waves in V5 and V6, depth of $S$ in V1 increased four times and $S$ in V6 only $1 \mathrm{~mm}$. (C) After four days on digoxin: ÂRS $+80^{\circ}$, transitional complex in V4, q waves in V4, V5, and V6 and a deep $\mathrm{S}$ in right chest leads.

In the first tracing the left ventricular hypertrophy is overshadowed by the marked right ventricular dilatation, but as the congestive failure clears the signs of left ventricular hypertrophy become very obvious.

\section{SUMMARY}

Twenty-three complete electrocardiograms of cases of primary endocardial fibroelastosis proven at necropsy are analysed.

There was a high incidence (16 cases) of left ventricular strain in hearts with vertical or semivertical electrical position.

Right ventricular hypertrophy occurred relatively commonly either in a pure form (4 cases) which might or might not be replaced later by left ventricular hypertrophy, or in the form of combined ventricular hypertrophy (3 cases).

There was a frequent alteration of the $P$. wave (14 cases) indicating right and/or left atrial hypertrophy or dilatation.

The value of the electrocardiogram as an aid to the differential diagnosis of endocardial fibroelastosis from a number of clinically similar conditions in infancy has been emphasized.

The authors wish to express their special appreciation to Dr. E. C. Lambert of the Children's Hospital, Buffalo, New York, Dr. A. L. Johnson of the Children's Memorial Hospital, Montreal, and Dr. Helen Taussig of Johns Hopkins Hospital, Baltimore for supplying electrocardiograms; without their generous co-operation this study would not
have been possible.

Owing to space limitations, a table containing the electrocardiographic details of the individual cases has been omitted. It will be available with the authors' reprints. 


\section{REFERENCES}

Adams, F. H., and Katz, B. (1952). J. Pediat., 41, 141.

Bland, E. F., White, P. D., and Garland, T. (1933). Amer. Heart J., 8, 787.

Blumberg, R. W., and Lyon, R. A. (1952). Amer. J. Dis. Child., 84, 291.

Bonham-Carter, R. E., Swyer, P. R., and Pugh, R. C. B. (1952). Lancet, 1, 311.

Clément, R., Gerbeaux, J., and Couvreur, J. (1952). Presse Méd., 60, 1767.

Collier, F. C., and Roshan, P. D. (1951). Pediatrics, 7, 175.

Craig, J. M. (1949). Bull. Inter. Assoc. of Med. Museums, 30, 15.

Dagonet, Y. (1952), Arch. Mal. Coeur., 45, 7.

Edmonds, H. W., and Seelye, W. B. (1951). Pediatrics, 7, 651.

Edwards, J. E. (1953), In Pathology of the Heart (ed. S. E. Gould). P. $420 . \quad$ Charles C. Thomas, Springfield, Ill.

Eidlow, S., and MacKenzie, E. R. (1946). Amer. Heart J., 32, 243.

Emery, J. L., and Illingworth, R. S. (1951). Arch. Dis. Childhood, 26, 304.

Gasul, B. M., and Loeffler, E. (1949), Pediatrics, 4, 498.

Glynn, L. E., and Reinhold, J. D. L. (1950). Arch. Dis. Childhood, 25, 170.

Gouley, B. A. (1950). Amer. Heart J., 40, 630.

Gros, G., Gordon, A., and Miller, R. (1951). Pediatrics, 8, 349.

Hartenstein, H., and Freeman, D. J. (1952). Amer. J. Dis. Child., 83, 774.

Hill, W. T., and Reilly, W. A. (1951). Amer. J. Dis. Child., 82, 579.

Holzmann, M. (1952). Clinical Electrocardiography. P. 369. London, Staples Press.

Johnson, F. R. (1952). Arch. Path., 54, 237.

Katz, B. E., and Adams, F. H. (1953). Amer. J. Dis. Child., 86, 186.

Kaunitz, P. E. (1947). Amer. Heart J., 33, 182.

Keith, J. D. (1954). Unpublished observation.

Keitzer, D. P. R., and Rochat, R. R. (1952). Amer. J. Dis. Child., 83, 769.

Lambert, E. C., Shumway, C. N., and Terplan, K. (1953). Pediatrics, 11, 255.

Lewis, K. C. (1951). J. Pediat., 39, 698

Leteer, C. R. (1953). Ann. Int. Med., 38, 573.

Lyon, R. A., Johansmann, R. J., and Dodd, K. (1946). Amer. J. Dis. Child., 72, 675.

Metianu, C., Guillemot, R., Durand, M., and Bardin, P. (1954). Sem. Hôp., 30, 434.

Miller, R. A. (1954). Ped. Clin. N. Amer., p. 61.

McKinley, H. I., Andrews, J., and Neill, C. A. (1951). Pediatrics, 8, 828.

Nestor, J. Q., Folston, M. J., and Howard, W. A. (1953). Clin. Proc. Child. Hosp. Washington, D.C., 9, 11.

Prec. K. J., and Cassels, D. E. (1952). J. Pediat., 41, 451.

Schlichter, J., Hellerstein, H. K., and Katz, L. N. (1954). Medicine, 33, 43.

Schweisguth, O., and Nouaille, J. (1952). Sem. Hôp., 28, 37.

Stadler, H. E., Reid, C. A., and Freidman, H. P. (1950). J. Pediat., 36, 370.

Taussig, H. B. (1953). Personal communication.

Vulliamy, D. G. (1947). Brit. Heart J., 9., 161.

Weinberg, T., and Himelfarb, A. J. (1943). Bull. Johns Hopkins Hosp., 72, 299.

Zeigler, R. F. (1951). Electrocardiographic Studies in Normal Infants and Children. Charles C. Thomas, Springfield, Ill. 